\title{
STUDY OF THE STATE OF THE ISSUE OF INCREASING THE QUALITY OF ELECTRIC ENERGY IN THE POWER SUPPLY SYSTEMS
}

\author{
Raxmatillo Karimov ${ }^{1 *}$ \\ ${ }^{1}$ Tashkent state technical university named after Islam Karimov, 100095, Uzbekistan, Tashkent, University St. 2A
}

\begin{abstract}
This article examines the importance of ensuring the quality of electricity and considers the possibility of using a system for monitoring the quality of electricity in the power supply system. Based on the results of the study, it was found that the use of contactless switching devices as switches of sections of windings of power transformers allows you to abandon current-limiting reactors and resistors. This is achieved by the fact that the switching of the windings occurs at the moment the load current passes through zero.
\end{abstract}

\section{Introduction}

In modern conditions, ensuring the quality of electricity is of particular relevance, because it is one of the most important conditions for the economical and long-term operation of electrical equipment at enterprises of the national economy and among household consumers, i.e. among the population $[1,2,3]$.

The energy monitoring system is a modern tool to improve the level of energy efficiency. Such a system creates a real basis for reducing electricity costs, subject to the implementation of energy saving projects. Energy monitoring is one of the functions of energy management, aimed at compliance with the norms, rules and regimes of energy use [1, 2, 3, 4].

Requirements for the electromagnetic environment in which electrical receivers operate are standardized by a standard that establishes permissible levels of interference in the electrical network, which characterize the quality of electricity and are called indicators of the quality of electricity. Deviation of the power quality indicators from the permissible values leads to a decrease in the service life of electrical equipment and the efficiency of its operation $[4,5]$.

Most of the phenomena occurring in electrical networks and deteriorating the quality of electrical energy occur in connection with the peculiarities of the joint operation of electrical receivers and the electrical network. The nature of changes in the parameters of the electrical network mode can be different and directly affects the indicators of the quality of electricity $[1,2,3]$ :

1. Changing the load in accordance with its schedule affects the voltage deviation;

2. Abruptly variable nature of the load - on voltage fluctuations;
3. Asymmetric distribution of the load over the phases of the electrical network - for voltage unbalance in a three-phase system;

4. Non-linear load - on the non-sinusoidal shape of the voltage curve.

With regard to these phenomena, consumers of electrical energy have the ability to influence its quality in one way or another. Everything else that degrades the quality of electrical energy depends on the characteristics of the network, climatic conditions or natural phenomena [5].

The deviation of power quality indicators from the standardized values not only worsens the operating conditions of electrical equipment of power supply organizations and electricity consumers, but also leads to significant damage both in industry and in the domestic sector. Electrical networks of general-purpose power supply systems are used to supply electrical receivers for various purposes. The most common types of electrical receivers that are widely used in urban electrical networks are electric motors and lighting installations. Also, electrothermal installations and valve converters are becoming more and more widespread $[3,5,6]$.

A characteristic feature of modern cities is an increase in the proportion of household loads, which have a specific effect on the indicators of the quality of electricity in electrical networks.

For the Republic of Uzbekistan, a specific property of electricity consumption in urban networks is the high consumption of electricity by air conditioners and other household devices. Compared to European countries, especially Germany, this is striking. Since in the aforementioned country, air conditioners are practically not used both in private houses and in public buildings. The random nature of voltage changes in networks with a large specific gravity of loads dictates special requirements for voltage quality $[2,3,5]$.

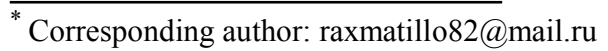




\section{Basic requirements for indicators of the quality of electrical energy}

Currently, electrical energy is used in all types of production processes of the country's economy and spheres of human life and is directly involved in the creation of other types of products. Each electrical receiver is designed to operate at certain parameters of electrical energy: rated frequency, voltage, etc., therefore, for its normal operation, the required quality of electrical energy must be provided $[3,5,6]$.

The quality of electricity is determined by a set of characteristics at which electrical receivers can operate normally and perform their functions. The quality of electrical energy can vary depending on the time of day, weather and climatic conditions, changes in the load of the power system, the occurrence of emergency modes in the network, etc.

Often the reason for the deterioration in the quality of electricity generated by power plants is the poor technical condition of power transmission lines and transformer substations, as well as the remoteness of consumers from the power source, etc [3,5].

The solution to the problem of power quality should be based on a technical and economic comparison of the effect of measures to improve the quality and the inevitable additional costs $[1,2,3,5]$.

The quality of electricity is assessed according to technical and economic indicators, taking into account the damage from low-quality electricity $[3,5]$ :

- technological damage caused by undersupply of products, disruption of the technological process of electricity consumers - damage in the power supply systems of consumers;

- electromagnetic damage from low-quality electricity, expressed in an increase in electricity losses and disruption of electrical equipment - damage in the power industry.

The quality of electricity is associated with reliability, since the power supply regime is considered normal, in which consumers are provided with electricity of standardized quality, the required quantity and without interruption [3].

There are four types of modes:

1) normal modes in which deviations of the power quality parameters from their nominal values do not go beyond the long-term permissible limits;

2) temporarily permissible modes characterized by current overloads, voltage deviations, etc., which are either included in the design calculations (for example, systematic overloads during daily maximums), or are allowed for a certain limited time without significant damage to the network and receivers powered from it;

3) emergency modes, characterized by overcurrents dangerous for network elements or other inadmissible phenomena; such modes usually occur when network elements are damaged (in case of insulation violations, when conductors are broken, etc.) and have a transient (unsteady) character;

4) post-emergency modes, which include both transient processes arising from manual or automatic power recovery (caused, for example, by the simultaneous self-starting of a large number of power consumers), and steady-state modes in new, often power-limited conditions.

For all of the listed types of modes, the power quality indicators or their permissible values for magnitude and duration are normalized $[2,5]$.

In Uzbekistan, indicators and standards for the quality of electrical energy in electrical networks of general-purpose power supply systems of alternating three-phase and single-phase current with a frequency of $50 \mathrm{~Hz}$ at the points to which electrical networks or electrical installations of consumers are connected are established by the Interstate Standard GOST 32144-2013 « Electric Energy. Electromagnetic compatibility of technical means. Electricity quality standards in generalpurpose power supply systems» $[2,3]$.

According to GOST 32144-2013, the main indicators of the quality of electricity are $[1,2,3]$ :

- frequency deviation;

- steady-state voltage deviation;

- voltage fluctuations, characterized by the range of voltage change and the dose of flicker;

- coefficient of the $n$-th harmonic component of the voltage;

- the distortion factor of the sinusoidal voltage curve;

- negative sequence voltage unbalance factor;

- zero sequence voltage unbalance factor;

- the duration of the voltage dip;

- impulse voltage;

- temporary overvoltage factor.

When determining power quality indicators, it should be borne in mind that the main quality indicators, in order to avoid long-term disruption of the normal operation of electrical receivers, should not go beyond their normal values for at least $95 \%$ of the time every day, and in post-emergency modes - beyond the maximum values.

At the terminals of power receivers that are sources of electromagnetic interference, changes in power quality indicators are allowed within wider limits than those specified in GOST 32144-2013, if this does not lead to a violation of the normalized power quality for other power receivers, and are established by agreements between power supply enterprises and consumers of electricity $[1,8]$.

In emergency modes, short-term power quality indicators are allowed beyond the established limits (voltage drop down to zero level, frequency deviation up to $5 \mathrm{~Hz}$, etc.) with their subsequent recovery to the level required in post-emergency modes $[2,9,10]$.

\section{Classification of electrical consumers by the impact on the indicators of the quality of electricity}

Deviations of power quality indicators from standardized values worsen the operating conditions of electrical equipment of power supply organizations and electricity consumers, can lead to significant losses both in industry 
and in the domestic sector, and cause, as already noted, technological and electromagnetic damage $[3,5,11]$.

The most typical types of electrical receivers that are widely used in enterprises of various industries are electric motors and electric lighting installations.

Electro thermal installations are widely used, as well as valve converters used to convert alternating current into direct current $[3,6]$. Direct current in industrial plants is used to power DC motors, for electrolysis, in galvanic processes, in some types of welding, etc.

Electric motors are used in drives of various production mechanisms. In installations that do not require speed control during operation, AC electric drives are used: asynchronous and synchronous electric motors $[6,7,12]$.

Electric lighting installations with incandescent, fluorescent, arc, mercury, sodium, xenon lamps are used at all enterprises for indoor and outdoor lighting, for the needs of city lighting, etc.

$\mathrm{AC}$ electric arc and resistance welding machines are single-phase, non-uniform and non-sinusoidal loads with a low power factor: 0.3 for arc welding and 0.7 for resistance. Welding transformers and low-power devices are connected to a $380 / 220 \mathrm{~V}$ network, more powerful ones - to a 6-10 kV network $[11,13]$.

By virtue of the specificity of their regulation, valve converters are consumers of reactive power (the power factor of valve converters of rolling mills ranges from 0.3 to 0.8 ), which causes significant voltage deviations in the supply network; the non-sinusoidal factor during the operation of thyristor converters of rolling mills can reach values of more than $30 \%$ on the $10 \mathrm{kV}$ side of the voltage supplying them; valve converters do not affect the voltage symmetry due to the symmetry of their loads $[3,5,13]$.

Electric welding installations can cause disruption of normal working conditions for other electrical receivers. In particular, welding machines, the power of which currently reaches $1500 \mathrm{~kW}$ per unit, cause significantly greater voltage fluctuations in electrical networks than, for example, the start of asynchronous motors with a squirrel-cage rotor. In addition, these voltage fluctuations occur for a long time and with a wide frequency range, including in the most unpleasant range for electric lighting installations (about $10 \mathrm{~Hz}$ ) [5, 6, 8].

Electro thermal installations, depending on the heating method, are divided into groups: arc furnaces, resistance furnaces of direct and indirect action, electronic smelting furnaces, vacuum, slag remelting, induction furnaces. This group of electrical consumers also has an adverse effect on the supply network, for example, arc furnaces, which can have a capacity of up to $10 \mathrm{MW}$, are currently being built as single-phase. This leads to a violation of the symmetry of currents and voltages (the latter occurs in connection with voltage drops across the network resistances from currents of different sequences). In addition, arc furnaces, like valve installations, are non-linear electrical receivers with low inertia. Therefore, they lead to non-sinusoidal currents, and, consequently, voltages [8, 13, 14$]$.

The modern electrical load of an apartment (cottage) is characterized by a wide range of household electrical appliances, which, according to their purpose and influence on the electrical network, can be divided into the following groups: passive consumers of active power (incandescent lamps, heating elements of irons, stoves, heaters); electrical receivers with asynchronous motors operating in three-phase mode (drive of elevators, pumps - in the water supply and heating system, etc.); electrical receivers with asynchronous motors operating in singlephase mode (compressor drive for refrigerators, washing machines, etc.); electrical receivers with collector motors (drive of vacuum cleaners, electric drills, etc.); AC and DC welding units (for repair work in a workshop, etc.); rectifying devices (for charging batteries, etc.); radio electronic equipment (televisions, computer equipment, etc.); high-frequency installations (microwave ovens, etc.); fluorescent lighting lamps [13, 14, 15].

The impact of each individual household electrical consumer is insignificant, while the aggregate of electrical consumers connected to the $0,4 \mathrm{kV}$ buses of the transformer substation has a significant effect on the supply network.

\section{The influence of low indicators of the quality of electrical energy on the operation of electrical consumers}

Influence of voltage deviations. Voltage fluctuations have a significant impact on the operation of induction motors, which are the most common electrical receivers in industry $[1,2,12]$.

For motors operating at full load, lower voltage leads to a decrease in speed, which affects the overall performance of the machines. With a significant decrease in voltage at the terminals of motors operating at full load, the moment of resistance of the mechanism can exceed the torque, which leads to the "overturning" of the motor, i.e. to stop it.

In addition, a decrease in voltage also worsens the conditions for starting the engine, since this reduces its starting torque $[3,5,16]$.

In the case of a decrease in the voltage at the motor terminals, the reactive magnetizing power decreases (by $2-3 \%$ with a voltage decrease of $1 \%$ ), with the same power consumption, the motor current increases, which causes insulation overheating.

A decrease in voltage also leads to a noticeable increase in reactive power lost in the leakage reactances of lines, transformers and induction motors [7, 13, 16].

An increase in the voltage at the motor leads leads to an increase in the reactive power consumed by them. On average, for each percentage increase in voltage, the consumed reactive power increases by $3 \%$ or more (mainly due to an increase in the no-load current of the engine), which in turn leads to an increase in active power losses in the elements of the electrical network.

Incandescent lamps are characterized by nominal parameters: power consumption, luminous flux, luminous efficiency (equal to the ratio of the luminous flux emitted by the lamp to its power) and average nominal service life. These indicators largely depend on the voltage at the terminals of the incandescent lamps. 
With a decrease in voltage, the luminous flux decreases. When the voltage rises above the nominal, the luminous flux, lamp power and luminous efficiency increase, but the service life of the lamps sharply decreases and as a result they quickly burn out. In this case, there is an overspending of electricity.

Changes in voltage lead to corresponding changes in luminous flux and illumination, which ultimately have an impact on labor productivity and human fatigue [9].

Fluorescent lamps are less sensitive to voltage fluctuations. With an increase in voltage, the power consumption and luminous flux increase, and with a decrease, they decrease, but not to the same extent as with incandescent lamps. At a reduced voltage, the ignition conditions of fluorescent lamps deteriorate, so their service life, determined by spraying the oxide coating of the electrodes, is reduced both with negative and positive voltage deviations [13, 14, 17].

With voltage deviations of $10 \%$, the service life of fluorescent lamps is reduced on average by $20-25 \%$. A significant drawback of fluorescent lamps is their consumption of reactive power, which increases with increasing voltage supplied to them.

Voltage deviations negatively affect the quality of work and the service life of household electronic equipment (radios, televisions, telephone and telegraph communications, computer equipment) $[1,2,3,5]$.

Valve converters usually have a DC automatic control system by phase control. When the voltage in the network increases, the control angle automatically increases, and when the voltage decreases, it decreases. A $1 \%$ increase in voltage leads to an increase in the reactive power consumption of the converter by about 1 $1.4 \%$, which leads to a deterioration in the power factor. At the same time, other indicators of valve converters with increasing voltage improve, and therefore it is beneficial to increase the voltage at their terminals within the permissible values $[7,8,16]$.

Electric ovens are sensitive to voltage fluctuations. Lowering the voltage of electric arc furnaces, for example, by $7 \%$ leads to a 1.5 -fold lengthening of the steel melting process. An increase in voltage above 5\% leads to excessive consumption of electricity.

Voltage fluctuations have a negative effect on the operation of electric welding machines, for example, for spot welding machines, when the voltage changes by $15 \%, 100 \%$ product rejects are obtained.

Influence of voltage fluctuations. Lighting devices, especially incandescent lamps and electronic equipment, are among the most sensitive to voltage fluctuations.

Blinking of light sources (flicker effect) causes an unpleasant psychological effect, eye fatigue and the body as a whole. This leads to a decrease in labor productivity, and in some cases to injury $[3,5,18]$.

With the same voltage fluctuations, the negative effect of incandescent lamps is manifested to a much greater extent than gas-discharge lamps. Voltage fluctuations of more than $10 \%$ can lead to extinguishing of gas discharge lamps. Their ignition, depending on the type of lamps, occurs after a few seconds or even minutes $[2,3]$.
Voltage fluctuations disrupt normal operation and reduce the service life of electronic equipment: radios, televisions, telephone and telegraph communications, computer equipment, X-ray equipment, radio stations, television stations, etc.

With significant voltage fluctuations (more than $15 \%$ ), the conditions for the normal operation of electric motors can be violated, the contacts of magnetic starters may fall off with a corresponding shutdown of the running motors $[5,18]$.

Voltage fluctuations with a swing of $10-15 \%$ can lead to failure of capacitor banks, as well as valve converters.

Influence of voltage unbalance. Asymmetrical load currents flowing through the elements of the power supply system cause asymmetric voltage drops in them.

The single-ended operation is of particular importance for three-phase asynchronous motors. The resistance of the negative sequence of electric motors is approximately equal to the resistance of the stalled motor and, therefore, 5-8 times less than the resistance of the positive sequence. Negative sequence currents are superimposed on positive sequence currents and cause additional heating of the stator and rotor, which leads to accelerated aging of the insulation and a decrease in the available motor power (decrease in the efficiency of the motor). Thus, the service life of a fully loaded asynchronous motor operating at a voltage unbalance of $4 \%$ is reduced by 2 times. With a voltage unbalance of $5 \%$, the available motor power is reduced by $5-10 \%[2$, $5,12]$.

In case of asymmetry of the mains voltages in synchronous machines, along with the occurrence of additional losses of active power and heating of the stator and rotor, dangerous vibrations can occur as a result of the appearance of alternating torques and tangential forces pulsating with a double frequency of the mains $[16,18,19]$.

Voltage unbalance significantly worsens the operating modes of multiphase rectifier rectifiers: the ripple of the rectified voltage significantly increases, the operating conditions of the pulse-phase control system of thyristor converters deteriorate $[5,9,14]$.

Capacitor installations with unbalanced voltages are unevenly loaded with reactive power in phases, which makes it impossible to fully use the installed capacitor power. In addition, capacitor banks in this case reinforce the already existing asymmetry, since the output of reactive power to the network in the phase with the lowest voltage will be less than in the other phases (in proportion to the square of the voltage on the capacitor bank) $[5,8]$.

Voltage unbalance also significantly affects singlephase electrical receivers, if the phase voltages are unequal, then, for example, incandescent lamps connected to a phase with a higher voltage have a higher luminous flux, but a significantly shorter service life compared to lamps connected to a phase with a lower voltage $[2,16]$.

Voltage unbalance complicates the operation of relay protection, leads to errors in the operation of electricity meters, etc. 
Influence of non-sinusoidal voltage. The currents of higher harmonics, passing through the network elements, create voltage drops in the resistances of these elements and, superimposed on the main voltage sinusoid, lead to distortions of the voltage waveform at the nodes of the electrical network $[1,2,15]$.

Higher harmonics of current and voltage cause additional losses of active power in all elements of the power supply system: in power lines, transformers, electrical machines, static capacitors, since the resistances of these elements depend on frequency [12, $20]$.

Higher harmonics cause:

- parasitic fields and electromagnetic moments in synchronous and asynchronous motors, which degrade the mechanical characteristics and efficiency of the machine;

- accelerated aging of insulation of electrical machines, transformers, cables;

- deterioration of the power factor of electrical receivers;

- deterioration or malfunction of automation devices, telemechanics, computer equipment and other devices with electronic elements;

- measurement errors of electricity meters, which lead to incomplete metering of consumed electricity;

- malfunction of the valve converters themselves at a high level of higher harmonic components.

Influence of frequency deviation. The strict requirements of the standard for deviations in the frequency of the supply voltage are due to the significant effect of the frequency on the operating modes of electrical equipment, the course of production processes $[1,2,3]$.

The electromagnetic component of the damage is caused by an increase in active power losses in electrical networks and an increase in the consumption of active and reactive power (a decrease in frequency by $1 \%$ increases losses in electrical networks by $2 \%$ ).

The technological component of the damage is mainly caused by the under-production of their products by industrial enterprises and the cost of additional time for the enterprise to complete the task. According to expert estimates, the value of technological damage is an order of magnitude higher than the electromagnetic one $[5,15]$.

An analysis of the work of enterprises with a continuous production cycle showed that most of the main technological lines are equipped with mechanisms with constant and fan moment of resistances with asynchronous motors. The rotational speed of the motor rotors is proportional to the change in the mains frequency, and the performance of the technological lines depends on the motor speed [2, 12].

Such electrical receivers as incandescent lamps, resistance furnaces, electric arc furnaces practically do not react to frequency changes.

Frequency deviations have a negative effect on the operation of electronic equipment: a frequency deviation of more than $+0.1 \mathrm{~Hz}$ leads to brightness and geometric background distortions of the television image, frequency changes from 49.9 to $49.5 \mathrm{~Hz}$ entail an almost fourfold increase in the permissible range of the television signal to background noise [5, 9].

In addition, the reduced frequency in the electrical network also affects the service life of equipment containing elements with steel (electric motors, transformers, reactors with a steel magnetic core), due to an increase in the magnetizing current in such devices and additional heating of steel cores [16].

Influence of electromagnetic interference. In generalpurpose power supply systems, electronic and microelectronic control systems, microprocessors and computers are widely used, which has led to a decrease in the level of noise immunity of control systems for electrical receivers and a sharp increase in the number of their failures. The main cause of failures is the effect of electromagnetic transient noise arising from electromagnetic transient processes both in power grid networks and in urban and industrial electrical networks $[2,20]$.

\section{Analysis of recent research and publications}

An analysis of recent studies and publications shows that in the context of improving market relations in the electric power industry, the task of monitoring the quality of electricity based on the measurement of indicators of the quality of electricity in accordance with GOST 13109-97 becomes urgent. The capabilities of modern technologies allow solving this problem in the monitoring mode $[1,2,5]$.

Thus, urban electrical networks have a significant amount of electrical, the predicted significant increase in household consumption in the cities of Uzbekistan in the future, as well as an increase in the urban population confirm the urgency of the problem of electricity quality. Further saturation of apartments with power receivers of increased power will exacerbate the issues of power quality in distribution networks, equipment that is located in multi-storey buildings. The random nature of the switching on of household appliances connected to a single-phase network leads to a significant asymmetry of phase loads. At the same time, most electrical consumers have a nonlinear current-voltage characteristic, which leads to a distortion of the voltage waveform. Electricity consumption for indoor lighting accounts for more than $50 \%$ of the total consumption of household electricity receivers $[5,8]$.

Consumers can be a source of interference, the level of which is different and requires research. Therefore, more than 10 measurements of power quality indicators were carried out in the $0.4 \mathrm{kV}$ networks in Tashkent. The measurements were carried out in accordance with the requirements of GOST 13109-97 [1, 2, 16]

The analysis of the power consumption of the studied enterprises of the national economy shows that the industry has significant reserves of power saving in the conditions of existing technologies. Thus, a study was carried out on the power consumption of the general house, lighting, elevator and apartment loads, taking into account the quality of electricity $[3,4,5]$. 
The frequency deviation in the network meets the requirements for the quality of electrical energy. During the measurement time, it was maximum - $50.04 \mathrm{~Hz}$, minimum $-49.97 \mathrm{~Hz}$, with a normally permissible value of $49.80-50.20 \mathrm{~Hz}$.

The research results showed that the value of the steady-state voltage deviation in the network during the measurements was from $5.78 \%$ (during the hours of maximum load) to $13.8 \%$ (at night).

The short-term dose of flicker during the measurements did not exceed the permissible limits [13, $21]$.

Non-compliance of the value of the steady-state voltage deviation with the norms leads to a sharp reduction in the life of the lamps. The data we obtained correspond to the real value of the supply voltage in the lighting networks of most cities and, according to the research data, fluctuate between 185-256 V. At night (05 hours, ) the average voltage at the beginning of the lines was $237 \mathrm{~V}$.

Lamps can ignite and operate at a supply voltage $10 \%$ lower than the nominal with the correct type of control gear, however, to obtain the maximum and luminous efficiency, the mains supply voltage and the rated voltage of the ballast must be within $\pm 3 \%$, and voltage fluctuations $\pm 5 \%$, permissible for short period of time [4, 11].

For the coefficient of the n-th harmonic component of the voltage in the studied network, violations were recorded in more than $20 \%$ of observations. The voltage unbalance factor in the reverse sequence does not meet the requirements for the quality of electrical energy during the measurements in more than $25 \%$ of observations. When considering in detail the reasons for the deterioration in power quality indicators, several reasons for the decline in power quality can be identified. The most common of these are $[18,19]$ :

1. Violation by consumers of the requirements of the rules for the use of electricity, namely:

- use of home-made (hand-made) equipment, including welding machines with a capacity of more than $10 \mathrm{~kW}$. When carrying out measurements using such devices, a decrease in the voltage in the network to 160 volts in the welding mode is observed;

- installation and use by consumers of electrical equipment in excess of the capacity permitted by the agreement with Regional Electric Networks JSC. This parameter can be clearly seen in multi-storey apartment buildings. As the experience of Regional Electric Networks JSC shows, today more than $70 \%$ of apartments are equipped with electric water heaters with a capacity of 1 to $3 \mathrm{~kW}$, an iron with a capacity of 0.7 to $2.5 \mathrm{~kW}$, an automatic washing machine with a capacity of 1.5 to $3 \mathrm{~kW}$ and other equipment. The installed capacity of the equipment of an average apartment is at least $4.5-5 \mathrm{~kW}$ today, although according to the current design standards for the power supply of residential buildings that are not equipped with electric stoves, and in accordance with the agreement between the subscriber with the power supply organization, the permitted installed capacity of electrical consumers for 1 apartment is taken as $3 \mathrm{~kW}$. Exceeding the installed capacity leads to a significant decrease in voltage and a deterioration in the quality of power $[4,18,21]$.

2. Insufficient volumes of capital repairs and reconstruction of networks of power supply organizations.

3. Lack of major repairs and modernization of intrabuilding networks of multi-storey apartment buildings.

Thus, the main violation of the standards for the quality of electricity at the studied enterprises of the national economy is voltage deviation, which causes the greatest damage to the operation of the installations of these enterprises, since work at a reduced voltage forces an increase in power, and an increase in voltage leads to a sharp reduction in the service life of their electrical receivers $[5,8]$.

\section{Non-contact AC voltage relay based on thyristors and optocouplers}

One of the most important indicators of power quality is the stability of the effective voltage value [5]. Using special technical means of regulation, transformers with load regulation or booster transformers, it is possible to achieve an improvement in the quality of voltage at consumers [2]. In this case, it becomes necessary to change the number of turns of the primary winding of the transformers. For this purpose, we recommend using a power device controlled by a non-contact relay, which allows the power thyristor to be switched under improved starting conditions [15].

At present, a set of technical solutions aimed at increasing the efficiency and quality of automation devices, radio engineering, telecommunications, industrial and consumer electronics, an expedient and useful measure is to replace electromechanical products (relays, potentiometers, rheostats, pushbutton and key switches) with more compact, durable, high-speed analogs $[5,8,16]$. The leading role in this direction is assigned to optoelectronic devices and devices [17, 18]. The fact is that very important technical advantages of transformers and electromagnetic relays (galvanic isolation of control and load circuits, reliable operation in powerful, high-voltage, high-current systems) are also inherent in optocouplers. At the same time, optoelectronic products are significantly superior to electromagnetic analogs in terms of reliability, durability, transient and frequency characteristics. The control of compact and high-speed optoelectronic transformers, switches, relays is confidently carried out using integrated microcircuits of digital technology without special means of electrical matching [14, 21].

We have developed contactless relays and voltage switches based on optoelectronic devices and thyristors. 


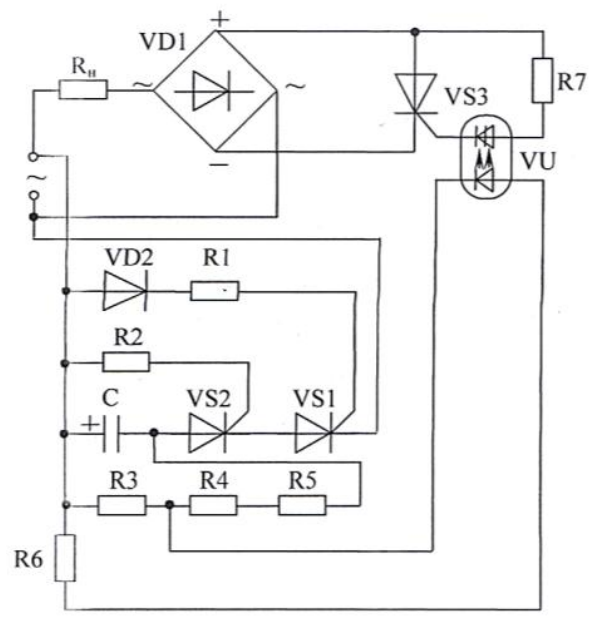

Fig.1. Scheme of a non-contact voltage relay with an optothyristor

Figure 1 shows a circuit of a non-contact voltage relay with an optothyristor. The relay contains a diode bridge $V D_{1}$ connected to the network in series with the load $R_{\text {load. }}$ A controlled thyristor $V S_{3}$ is included in the diagonal of the bridge. The control signals to the control electrode of the power thyristor are supplied through the resistor $R_{7}$ and the thyristor circuit of the $V U$ optocoupler $[15,22]$.

To connect the load to the network, it is necessary to apply a positive DC pulse to the control electrode of the power thyristor $V S_{3}$. In this case, the thyristor will be in a conducting state throughout the entire period of the alternating voltage and both half-waves of the alternating current flow through the load. If the control signal is removed, the thyristor is locked and the load is disconnected from the network $[8,16]$.

To control the state of the power thyristor, a thyristor optocoupler $V U$ is used, and the diode circuit of the optocoupler is connected through resistors $R_{6}, R_{3}, R_{4}, R_{5}$ to the capacitor plates, which in turn is connected to the network through two series-connected low-power controlled thyristors $V S_{2}, V S_{1}$. The control signal for the thyristor $V S_{1}$ is supplied from the network through the series-connected diode $V D_{2}$ and the resistor $R_{1}$, for $V S_{2}$ through the resistor $R_{2}[21,23]$.

The operating principle of the relay is as follows:

When a certain value of the input voltage is reached, the trigger signal on the control electrode of the thyristor $V S_{1}$ will be sufficient to open it, and the operating current of this thyristor opens the thyristor $V S_{2}$ in a jump. After opening the thyristors $V S_{1}, V S_{2}$, the capacitor $C$ is charged. From the capacitor plates through the resistors $R_{6}, R_{3}, R_{4}, R_{5}$, an unlocking signal is supplied to the diode circuit of the $V U$ optocoupler, while the thyristor circuit of this optocoupler opens, and a signal is sent to the control electrode of the power thyristor $V S_{3}$, which, when opened, turns on the load $R_{\text {load }}$ into the network [5].

The triggering moment of the thyristor $V S_{1}$ is regulated by selecting the resistor $R_{1}$.

This non-contact voltage relay was tested in the laboratory of the "Power Supply" Department of the Power Engineering Faculty of the Tashkent State Technical University named after Islam Karimov. In this case, they used as thyristors $V S_{1}, V S_{2}, V S_{3}-K U 201 L$, as a diode $V D_{2}-D 226 B$, as active resistances $R_{1}=160 \mathrm{k} \Omega$, $R_{2}=11 \mathrm{k} \Omega, R_{3}=68 \mathrm{k} \Omega, R_{4} ; R_{5}=15 \mathrm{k} \Omega, R_{6}=120 \mathrm{Ohm}$, $R_{7}=2.2 \mathrm{k} \Omega$, as capacitance $C=150 \mu \mathrm{F}$ at $300 \mathrm{~V}$, diode bridge $V D_{1}-K T S 405 A$, thyristor optocoupler $A O U 103 \mathrm{~V}$, $R_{\text {load }}=820$ Ohm $[15,22]$.

\section{Non-contact device for switching the booster transformer windings}

Known contact devices for turning on and off the winding of a booster transformer, consisting of a booster transformer and a block for turning on the winding [20]. The disadvantage of such devices is the use of an electroferromagnetic element and electromechanical keys in the control unit, which leads to an increase in the weight and dimensions of the entire device and to a decrease in the reliability of its operation $[15,22]$.

The problem is solved by the fact that a non-contact thyristor device for switching on the winding of a booster transformer, containing a diode bridge, in the diagonal of which a controlled power thyristor is included, is connected to the network in series with a booster winding. To the control electrodes of the power thyristor, control signals are fed through the resistor and the thyristor part of the optocoupler of the first voltage relay (I). The diode part of the optocoupler is connected through resistors to the plates of the capacitor, which in turn is connected to the network through two seriesconnected low-power controlled thyristors [13]. The control signal for one of them is supplied from the network through a series-connected diode and a resistor, and for the second through a resistor. The booster winding is disconnected from the network due to the action of the second voltage relay (II) containing an optocoupler, the diode circuit of which is connected to the capacitor plates of the second relay through a resistor, and the thyristor circuit is connected between the connection point of two resistances of the diode circuit of the first optocoupler and the capacitor plate of the first relay. The rest of the second relay circuitry is done as in the first relay $[16,22]$.

The implementation of a non-contact thyristor device for turning on and off the winding of the booster transformer according to the specified scheme provides the best weight and dimensions and high reliability [5, 20].

Figure 2 shows a schematic electrical diagram of a non-contact thyristor device for turning on and off the booster transformer winding. The device contains a diode bridge 1 , connected to the network in series with a booster winding 3 , a controlled thyristor 2 is included in the diagonal of the bridge, control signals are fed to the control electrode of the power thyristor through a resistor 4 and a thyristor circuit of an optocoupler 5 . The diode circuit of the optocoupler 5 is connected through resistors 6.7 to the plates of the capacitor 8 , which is connected in series with two low-power controlled thyristors 9.10. The control electrode of the low-power thyristor 10 is connected to the network through the series-connected resistor 12 and the diode 13 , and the 
control electrode of the low-power thyristor 9 is connected through the resistor 11 to the first plate of the capacitor 8. Between the connection point of the resistances 6.7 and the second plate of the capacitor 8 , the thyristor part of the optocoupler 20 is connected. The diode part of the optocoupler 20 is connected through a series-connected limiting resistor 21 to the plates of the capacitor 17 , which in turn is connected to the network through two series-connected low-power controlled thyristors 18,190 . The control signal to these thyristors is supplied in the same way as in the circuit of the first relay $[14,15,16]$.

A non-contact thyristor device for turning on and off the booster transformer winding works as follows. When a certain value of the input voltage is reached, the unlocking signal on the control electrode of the first relay will be sufficient to open the thyristor 10 , and the operating current of this thyristor opens the thyristor 9 in a jump. After opening the thyristors 9,10 , the capacitor 8 is charged. From the plates of the capacitor 8 through the resistor 6.7, an unlocking signal is supplied to the diode circuit of the optocoupler 5, while the thyristor circuit of this optocoupler is opened, and a signal is sent to the control electrode of the power thyristor 2, which, opening, turns on the booster winding 3 into the network. The moment of operation of thyristors 9, 10 and 18,19 is regulated by selecting the parameter of resistors 12 and $14[5,8]$.

With an increase in the input voltage, the booster winding is disconnected from the network due to the action of the second voltage relay containing an optocoupler 20. When the diode part of the optocoupler 20 is turned on, the thyristor part of the circuit is turned on, thereby closing the diode circuit of the optocoupler 5 to the resistor 6 , and this leads to the disconnection of the thyristor circuit of the optocoupler 5. This leads to the disconnection of the power thyristor 2 and the opening of the booster winding of the transformer from the network $[9,13]$.

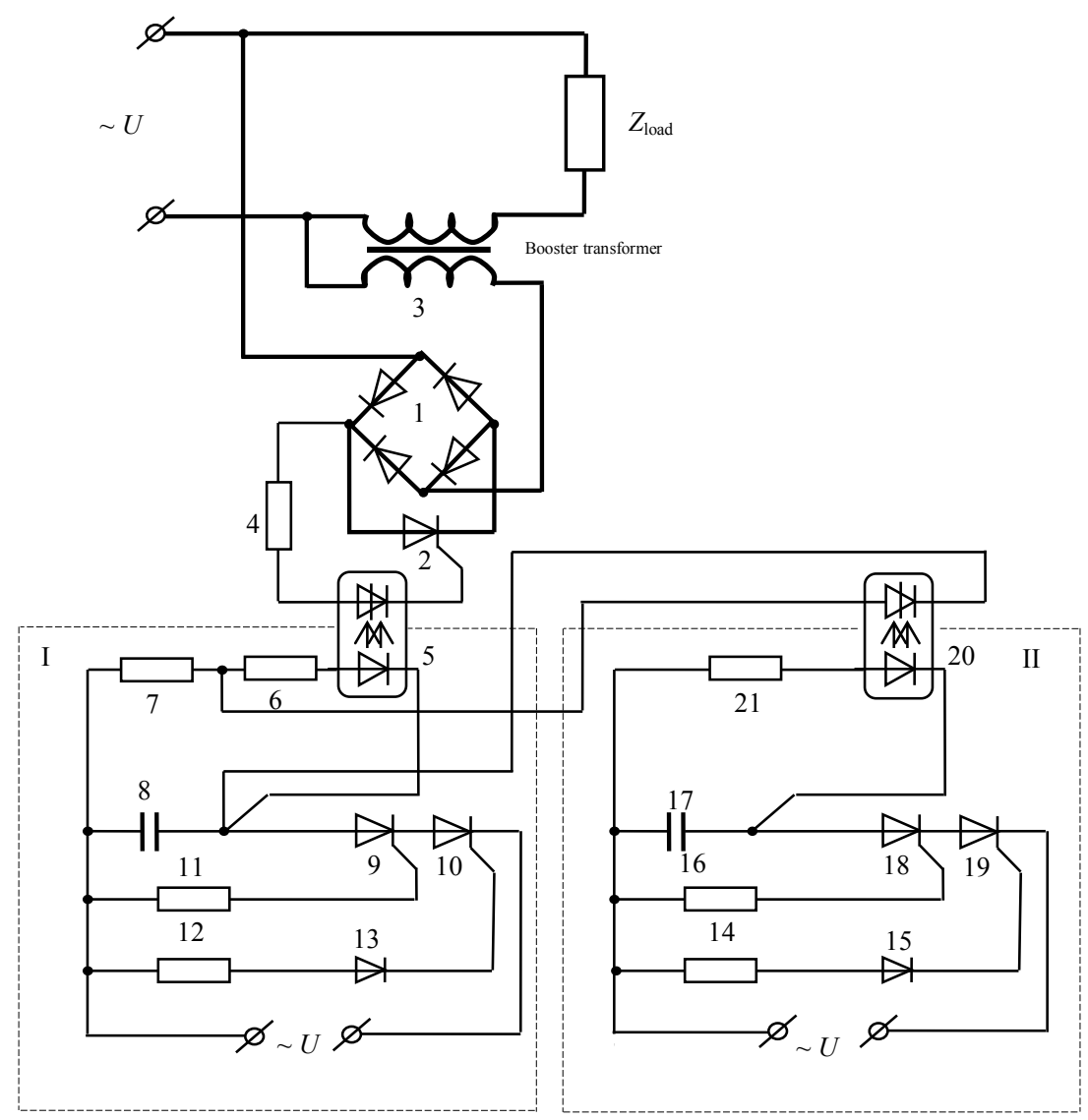

Fig.2. Schematic electrical diagram of a non-contact thyristor device for turning on and off the booster transformer winding

This non-contact thyristor device for turning on and off the booster transformer winding was tested in the laboratory of the "Power Supply" Department of the Power Engineering Faculty of the Tashkent State Technical University named after Islam Karimov. In this case, thyristors of the type $K U 202 Z H, K U 201 K$, $K U 202 N, K U 202 E, K U 202 I$ were used as thyristors 2, 9, $10,18,19$, respectively, as diodes $13,15-D 226 B$, as active resistances 4, 6,7,11,12,14,16,21 resistors for 820 Ohm, $5.1 \mathrm{kOhm}, 1.3 \mathrm{kOhm}, 6.8 \mathrm{kOhm}, 22 \mathrm{kOhm}, 24$ kOhm, $6.8 \mathrm{kOhm}, 20 \mathrm{kOhm}$, respectively, as capacities 8 and 17 - capacitors of alternating voltage for $500 \mathrm{~V}$. with a capacity of $2 \mu \mathrm{F}$, thyristor optocouplers $A O U 103 \mathrm{~V} 1$, diode bridge $K T s 402 \mathrm{~V}$ were used as optocouplers 5 and 20. Experimental studies have shown that the booster winding of transformer 3 was connected to the network 
at a voltage of $65 \mathrm{~V}$., and turned off at a voltage of $95 \mathrm{~V}$ $[22,23]$.

Figure 3 shows the input-output characteristics of this relay.

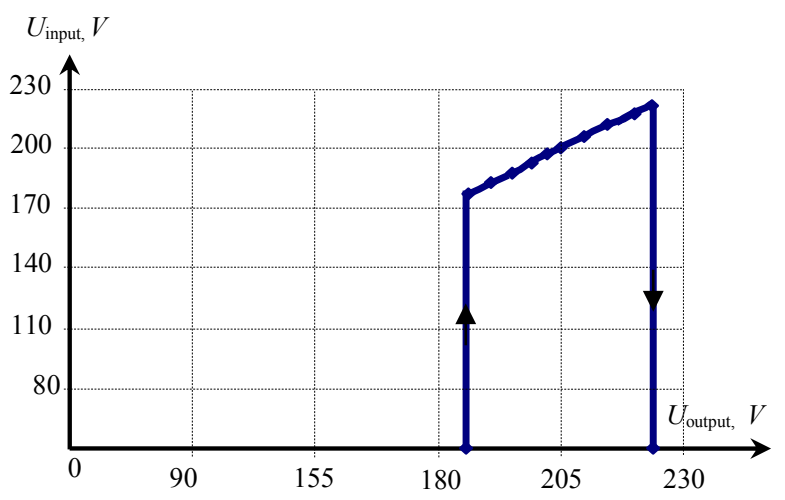

Fig.3. Characteristic "input-output" contactless voltage relay

\section{Conclusion}

1. Summarizing the above, we can conclude that ensuring the quality of electricity is a very urgent task today and monitoring the quality of electricity at industrial enterprises of the national economy and other organizations allows us to develop measures to improve the quality of electricity.

2. A review of the literature on non-contact equipment has shown the widespread use of contactless equipment in power supply systems, which ensure high reliability and energy savings.

3. We have developed various circuits of thyristor voltage relays with a non-sinusoidal and sinusoidal shape of the voltage curve at the load, experimentally investigated and proposed circuits and identified a promising version of a thyristor voltage relay, which can serve as a switch for the windings of a boost transformer. 4. The work offers circuits of a non-contact optical thyristor voltage relay and a switch of the booster transformer windings. A voltage stabilizer circuit is proposed to reduce the deviation and fluctuations of the mains voltage, while maintaining the sinusoidal shape of the voltage and current curve on the load.

\section{References}

1. Interstate standard GOST 13109-97. Protocol 12 dated November 21, 1997. - PP.27.

2. State standard of Uzbekistan O'z DSt 1044:2003. Protocol 05-19 dated July 18, 2003. - PP.27.

3. State standard of Uzbekistan O'z DSt 1050:2004. Protocol 05-02 dated January 30, 2004. - PP.53.

4. Sokolov V.S. Bulletin Promishlennaya energetika, 1, PP.25-29 (2004).

5. Usmanov E.G., Abduraimov E.Kh., Karimov R.Ch. Bulletin TSTU, Tashkent, 3-4, - PP.48-51, (2012).

6. Karimov R.Ch., Shamsiyev K., and others. IOP Conf. Series: Materials Science and Engineering, 883(1), 012142, (2020). doi:10.1088/1757-899X/883/1/012142
7. Karimov R.Ch., Shamsiyeva N. and others. IOP Conf. Series: Materials Science and Engineering, 883(1), 012120, (2020). doi:10.1088/1757-899X/883/1/012120

8. E.G.Usmanov, A.N.Rasulov, M.K.Bobojanov, R.Ch.Karimov. E3S Web of Conferences 139, 01079 (2019), doi.org/10.1051/e3sconf/201913901079

9. Karimov R.Ch. Technical science and innovation, 2, (2019). uzjournals.edu.uz/btstu/vol2019/iss2/8

10. Milovzorov V.P., Musolin A.K. Uchebnoe posobie, M.: Izd. Energoatomizdat, - S.247, (1986).

11. Hoshimov, F.A., Bakhadirov, I.I., Erejepov, M., Djumamuratov, B. (2019) Development of method for normalizing electricity consumption E3S Web Conf 139 doi:10.1051/e3sconf/201913901074

12. Rismuhamedov D., Tuychiev F. and others. IOP Conf. Series: Materials Science and Engineering, 883(1), 012140, (2020). doi:10.1088/1757-899X/883/1/012140

13. Bobojanov M.K., Usmanov E.G., Abduraimov E.H., Karimov R.Ch. European Science Review, 1-2. PP.210-212, (2018).

14. Karimov R.Ch. European Science review, 9-10, PP.144-146, (2015).

15. Abduraimov E.Kh., Karimov R.Ch. INNOVATION2016, Tashkent, - PP.128-129, (2016).

16. Sulliev A.X., Karimov R.Ch. Bulletin Tashkent Institute of Railway Engineers, Tashkent, 4. - PP.149154, (2018).

17. Bobojanov M.K., Rasulov A.N., Karimov R.Ch., Sattarov H.A. Bulletin Descendants of Mohammed AlKhwarizmi (ISSN: 2181-9211), Tashkent, 3(5), PP.106-109, (2018).

18. Rasulov A.N., Karimov R.Ch. European Science review, 9-10, - PP.140-143, (2015).

19. Rasulov A.N., Karimov R.Ch. EESJ, 4, - PP.174178, (2015), doi:10.12851/EESJ201508C05ART02

20. Abduraimov E.Kh., Karimov R.Ch., Ruzinazarov M.R. Certificate of official registration of the computer program DGU 05850, (2018).

21. Karimov R.Ch., Bobojanov M.K., Rasulov A.N., Usmanov E.G. E3S Web of Conferences, 139, 01039, (2019). doi.org/10.1051/e3sconf/201913901039

22. Usmanov E.G., Abduraimov E.Kh., Karimov R.Ch. Patent for invention of the Republic of Uzbekistan, IAP 05122, (2015).

23. Rasulov A.N., Karimov R.Ch. EESJ, 4, - PP.179183, (2015). doi:10.12851/EESJ201508C05ART01 